\title{
Desafios da permanência de estudantes LGBT+ na universidade: percepção de discentes de centro universitário amazônico
}

\author{
Challenges of LGBT+ students' stay at university: perception of students from a \\ amazonian university center
}

Desafíos de la estancia de los estudiantes LGBT+ en la universidad: percepción de los estudiantes de un centro universitario amazónico

Victor Serrate Capucce ${ }^{1 *}$, Jade Gomes da Costa Medeiros ${ }^{1}$, Anitha de Cássia Ribeiro da Silva ${ }^{1}$, Ítalo Diógenes Gomes da Silva ${ }^{1}$, Rafael Ademir Oliveira de Andrade ${ }^{1}$, Mariana Bezerra dos Santos ${ }^{1}$, Arlindo Gonzaga Branco Junior ${ }^{1,2}$.

\section{RESUMO}

Objetivo: Identificar os principais desafios para a permanência de alunos LGBT+ do curso de medicina e enfermagem de uma instituição privada do norte do país, determinando um paralelo entre a visão de docentes e discentes. Métodos: Trata-se de uma análise quantitativa, que teve como alvos de pesquisa alunos (as) e professores (as) de uma instituição particular de ensino superior do Norte do país, fazendo uso de questionários online para docentes e discentes, com 11 e 21 perguntas do tipo opção única, respectivamente. Foram duas semanas para coleta de dados, uma para cada alvo, dito isso, obteve-se 120 respostas de alunos e apenas um dos professores. Resultados: A análise das respostas mostrou que cerca de $20 \%$ dos alunos já cogitaram desistência do curso por conta de conflitos relacionados à sua orientação sexual, como $40 \%$ já souberam ou presenciaram algum ato de preconceito ou discriminação contra pessoas LGBT+ no ambiente educacional. Conclusão: Logo, assinala-se que a pessoa LGBT+ acumula desafios de diversas origens e inerentes à sua própria natureza.

Palavras-chave: Minorias sexuais e de gênero, Ensino superior, Graduação, Enfermagem, Medicina.

\begin{abstract}
Objective: To identify the main challenges for the permanence of LGBT + students in the medical and nursing course of a private institution in the north of the country, determining a parallel between the view of teachers and students. Methods: This is a quantitative analysis, whose research targets were students and teachers from a private higher education institution in the North of the country, using online questionnaires for teachers and students, with 11 and 21 single option questions, respectively. It took two weeks to collect data, one for each target, having said that, 120 responses were obtained from students and only one from the teachers. Results: The analysis of the answers showed that about $20 \%$ of the students have already considered dropping out of the course due to conflicts related to their sexual orientation, as $40 \%$ have known or witnessed some act of prejudice or discrimination against LGBT + people in the educational environment. Conclusion: Therefore, it is pointed out that the LGBT + person accumulates challenges from different origins and inherent to his own nature.
\end{abstract}

Keywords: Sexual and gender minorities, Higher education, Undergraduat, Nursing, Medicine.

${ }^{1}$ Centro Universitário São Lucas (UniSL), Porto Velho - RO.

*E-mail: victordlserrate@gmail.com

2 Universidade Federal de Rondônia (UNIR), Porto Velho - RO.

SUBMETIDO EM: 3/2021 


\section{RESUMEN}

Objetivo: Identificar los principales desafíos para la permanencia de estudiantes LGBT + en el curso de medicina y enfermería de una institución privada en el norte del país, determinando un paralelismo entre la visión de docentes y estudiantes. Métodos: Se trata de un análisis cuantitativo, el cual fue dirigido a estudiantes y docentes de una institución privada de educación superior en el norte del país, utilizando cuestionarios en línea para docentes y estudiantes, con 11 y 21 preguntas de opción única, respectivamente. Se necesitaron dos semanas para recopilar datos, uno para cada objetivo, dicho esto, se obtuvieron 120 respuestas de los estudiantes y solo una de los profesores. Resultados: El análisis de las respuestas arrojó que alrededor del $20 \%$ de los estudiantes ya ha considerado abandonar el curso por conflictos relacionados con su orientación sexual, ya que el $40 \%$ ha conocido o presenciado algún acto de prejuicio o discriminación contra personas LGBT + en el entorno educativo. Conclusión: Por lo tanto, se observa que la persona LGBT + acumula desafíos de diferentes orígenes e inherentes a su propia naturaleza.

Palabras clave: Minorías sexuales y de género, Enseñanza superior, Licenciatura, Enfermería, Medicina.

\section{INTRODUÇÃO}

A sigla LGBT+ representa as orientações sexuais que ultrapassam a visão tradicional, sendo cada letra correspondente as iniciais de lésbicas, gays, bissexuais, transexuais, transgênero, intersexo e queer, respectivamente (ROMERO MAE e JIMÉNEZ JRR, 2020). A orientação sexual é descrita como atração sexual, afetiva e emocional por diversos, iguais ou diferentes gêneros (GOMES TMC, et al., 2021).

O patriarcado, que molda as relações sociais e ideológicas, determina enquanto aceitável apenas uma matriz de comportamento afetivo, social e sexual, fomentando a LGBTfobia enquanto símbolo-forma que desencadeia a violência contra a população LGBT+ (VIEIRA JUNIOR JI e ALMEIDA JP, 2019). Ao serem considerados indivíduos que subvertem o padrão da cisnormatividade, essa população historicamente sofre marginalização, exclusão de espaços, são patologizadas, descritas como pervertidas e desviadas, uma vez que não se enquadram nos padrões hegemônicos da sexualidade colonialista (CORTES HM, et al., 2019).

Diante disso, a cultura patriarcal também adentra nos ambientes acadêmicos, manifestando os padrões formativos de masculinidade cultural e tradicionalmente dominantes nesses espaços (CALOU ALF, 2019). Esta reflexão levou aos autores a debater sobre o tema no meio acadêmico, primeiro com rodas de conversa e após com pesquisa literárias englobando reflexões sobre academia e a população LGBT+.

A inclusão da população LGBT+ nos circuitos onde há grande concentração de capital social, intelectual e econômico é geralmente marcada por ações preconceituosas e discriminatórias (SANTOS LES, et al., 2019) justamente por estes indivíduos terem sidos excluídos da matriz colonial de poder e de legitimação de formas de ser-existir (QUIJANO A, 2005). Dessa forma, a opressão sofrida por esse grupo tende socialmente a impedir o acolhimento, como também, o sentimento de pertencimento no âmbito acadêmico (VIEIRA JUNIOR Jl, et al., 2019).

Com isso, os grupos minoritários quando entram no ensino superior podem ter que lidar com as adaptações da nova realidade, como também, com o preconceito e discriminação de muitos docentes e discentes (VALENZUELA- VALENZUELA AV, CARTES-VELÁSQUEZ R, 2020). Desse modo, Walsh C (2009) chama de Interculturalidade passiva quando as diferença e diversidades são colocadas enquanto existentes desde que se sujeitem ao padrão, ou seja, um indivíduo da comunidade LGBTQ+ dentro da academia tende a ser aceito quando se encaixa (tanto na corporalidade, vestimenta e narrativas) no padrão da matriz de gênero esperado.

No ambiente escolar, os alunos LGBT+ podem sofrem com o bullying de gênero por meio de risadas, chacotas, exclusão e até mesmo agressão física, essas violências podem ser tão traumatizantes que desencadeia a omissão da identidade de gênero e sexual da vítima (VIEIRA M, 2015). Na vida universitária esse comportamento pode quase não se altera, com poucos entendendo 0 assunto e suas origens psicossociológicas, acaba se mantendo as formas de discriminação (LACERDA M, et al., 2002). Com isso 
pode-se sugerir uma "violência institucional", onde as escolas e universidades omitem, como também, a polícia, devido ao alto número de casos arquivados de violência contra a comunidade LGBT (CARRARA S e VIANNA A, 2006).

Grupos minoritários como o retrato aqui, possuem taxa de suicídio 2 a 7 vezes maior que o observado em estudos feitos com população heterossexual, esse fato pode ser justificado devido à exposição a ambientes hostis, em que vivencia discriminação e assédio, incluindo nos ambientes acadêmicos (CARVALHO KG, et al., 2019).

Nessa perspectiva, permitir o acesso e não possibilitar a permanência é impedir o direito à educação, com isso, muitos fatores impossibilita a permanência dos acadêmicos LGBT+ nas universidades, como, a criação de programas pedagógicos que não quebram a visão heterossexista, a concepção do ambiente escolar como espaço de repetição de desigualdade social e as condutas discriminatórias e de LGBTfobia reproduzidas por discentes e por funcionários (VIEIRA JUNIOR JI e ALMEIDA JP, 2019).

Dessa forma, o presente trabalho pretende avaliar os desafios da permanência de estudantes LGBT+ na universidade e refletir como estudantes de uma instituição de ensino superior do norte do país o percebem, a fim de entender a dinâmica dentro da instituição e promover medidas que contribuam com o contorno desse cenário.

\section{MÉTODOS}

Trata-se de uma pesquisa quantitativa e descritiva realizada em uma instituição de ensino superior privada do município de Porto Velho - Rondônia. A pesquisa incluiu alunos e professores do curso de Enfermagem e Medicina, maiores de 18 anos e que estão devidamente matriculados ou que possuem vínculo empregatício no momento da coleta de dados.

A coleta de dados foi realizada por meio da aplicação de dois questionários. Um questionário destinado aos alunos (SANTOS, 2017), composto por 21 questões objetivas do tipo opção única, que colheram dados socioeconômicos, acadêmicos e de gênero do público entrevistado.

Já o questionário destinado aos professores dos cursos de Medicina e Enfermagem continha 11 questões objetivas do tipo opção única que colheram dados acerca da percepção do corpo docente quanto à LGBTfobia na instituição, que também se valeram da Escala de Likert como método qualitativo. Entretanto, a pesquisa não obteve êxito quanto ao questionário disponibilizado aos docentes, mesmo com árdua divulgação e prolongamento do período para envio de respostas, somando duas semanas. Assim, não houve adersão dos professores aos seus respectivos questionários.

O envio do link de acesso a coleta de dados aos professores ocorreu durante 4 dias na semana ao longo de duas semanas, sendo encaminhado também uma mensagem de apresentação do auxiliar da pesquisa, explicação sobre a pesquisa, informação sobre o sigilo dos dados informados, uso apenas para fins científicos e possibilidade de recusa ou retirada dos dados já informados.

Ambos os questionamentos foram confeccionados na plataforma Formulários Google Forms sendo divulgado no campus da universidade via Qr Code e Whatsapp dos cursos estudados. A divulgação nos grupos de WhatsApp foi feita pelos auxiliares da pesquisa que separaram 4 dias na semana para encaminhar o link da plataforma Google formulário, junto com um texto de apresentação que introduzia sobre a pesquisa.

Estima-se que a mensagem de divulgação foi vista por mais de 500 pessoas, no entanto, o processo de adesão pode ter sido comprometido pelo medo dos alunos de clicar no link disponível, visto que, pesquisas online na instituição estavam entrando em voga durante o atual momento de pandemia de covid- 19 .

Por fim, os dados coletados foram salvos em planilhas no programa Microsoft Office Excel 2007 e Microsoft Office Word 2007. Após, comparou-se com a literatura e discussão dos resultados.

O projeto foi Aprovado pelo Comitê de ética em pesquisa sob CAAE 37157320.2.0000.0013 e Número do Parecer 4.291.349 aprovado no dia 22 de setembro de 2020. 


\section{RESULTADOS}

Participaram da coleta 120 discentes ao total, sendo $64,2 \%$ mulheres e $35,8 \%$ homens. A média das idades correspondeu a 20 anos, com a menor faixa etária representada por 18 anos e a maior por 40 anos. Analisando com quem os entrevistados residem, a maioria, $47,5 \%$, moram com a família, seguindo de $38,3 \%$ sozinhos, 10,8\% com amigos e 3,3\% com companheiro (a), respectivamente.

Ao questionar aos entrevistados se eles trabalham, 84,2\% afirmaram que não e 15,8\% disseram que sim. Analisando a renda familiar desses discentes, $42,5 \%$ possui de 5 salários mínimos ou mais, $23,3 \%$ de 2 a 3 salários mínimos, $18,3 \%$ de 3 a 4 salários mínimos, $14,2 \%$ de 1 a 2 salários mínimos e 1,7\% menos de um salário mínimo. Estes dados combinados nos afirmam que a amostra aqui analisada faz é composta por indivíduos de classe média e com a possibilidade de se dedicar ao estudo de forma integral.

Em relação ao grau de escolaridade da mãe dos participantes desse estudo, 32,5\% tem pós-graduação, $32,5 \%$ possui ensino superior completo, $12,5 \%$ porta diploma de ensino médio completo, $10 \%$ detém ensino fundamental incompleto, $6,7 \%$ dispõe de ensino médio incompleto, $3,3 \%$ possui ensino superior incompleto e $2,5 \%$ tem ensino fundamental completo. Quanto ao grau de escolaridade do pai, 30,1\% tem ensino médio completo, $18,7 \%$ pós-graduação, $15,4 \%$ ensino superior completo, $13,8 \%$ ensino fundamental incompleto, $8,1 \%$ ensino fundamental completo e ensino superior incompleto, $3,3 \%$ não frequentou a escola e $2,4 \%$ possui ensino médio incompleto.

Quando indagado o tipo de escola que os entrevistados estudaram, $53,7 \%$ destes disseram que em escola privada, $23,6 \%$ em escola privada e pública e $22,8 \%$ apenas na rede pública. Verificou-se, também, que $94,3 \%$ dos discentes são oriundos da zona urbana e 5,7\% da zona rural. Em relação à situação na qual os estudantes se encontram, atualmente, na instituição, $89,4 \%$ afirmaram que estão ativo-blocado e $10,6 \%$ ativodeslocado.

No que tange ao principal motivo dos discentes escolherem o atual curso, 75,6\% declarou identificação pelo curso, $12,2 \%$ pelo mercado de trabalho, $8,1 \%$ pela formação acadêmica, $3,3 \%$ pela ideologia do curso $\mathrm{e}$ $0,8 \%$ para obter um diploma. A contemplação de alguma bolsa estatal também foi avaliada, $59,3 \%$ não recebe nenhuma bolsa e 40,7\% recebe.

Com base na avaliação da assistência estudantil da instituição de ensino, no contexto do favorecimento para permanência no curso, $48,8 \%$ a considera regular, $27,5 \%$ bom, $11,7 \%$ ruim, $9,2 \%$ péssimo e 2,5\% ótimo - estes dados se somarmos os dados regular, ruim e péssimo temos um percentual de $69,7 \%$ de discentes que consideram não influentes ou de péssima qualidade a questão da assistência estudantil na instituição de ensino superior, o que nos leva a refletir sobre a questão da manutenção das classes menos abastadas no ensino superior.

Quanto à perspectiva após a conclusão do curso, 81,7\% pretende fazer especialização/residência, 8,3\% quer trabalhar como médico (a) /enfermeiro (a) em hospital privado ou público, 3,3\% almeja entrar no mestrado, 3,3\% quer realizar concurso público e 3,3\% cogita trabalhar como médico (a) /enfermeiro (a) em hospital público. Nestes dados temos algumas conclusões possíveis: a grande maioria pretende continuar os estudos com alguma remuneração (no caso da residência) e apenas $8,3 \%$ pretende se direcionar para 0 mercado de trabalho, o que é um reflexo da classe social de origem dos colaboradores, ainda $6,6 \%$ dos entrevistados querem entrar em um hospital público via concurso ou seleção, sendo este dado fundamental para pensarmos a democratização do acesso gratuito à saúde no Brasil tanto em espaços urbanos quanto rurais.

Em relação à orientação sexual, $55,8 \%$ dos entrevistados se afirmam heterossexual, $23,3 \%$ homossexual e $20,8 \%$ bissexual. Ao serem indagados se já presenciaram ou souberam de algum episódio de discriminação/preconceito contra pessoas LGBT+ dentro da instituição de ensino, 60\% dos entrevistados respondeu que não e $40 \%$ que sim.

Outras informações pertinentes acerca da visão dos estudantes para a posterior discussão encontram-se tabuladas (Tabela 1). 
Tabela 1 - Visão dos estudantes sobre os desafios da permanência do aluno LGBT+ no ambiente estudantil.

\begin{tabular}{|c|c|c|c|c|c|c|c|c|c|c|c|c|c|}
\hline \multirow[t]{2}{*}{ № } & \multirow[t]{2}{*}{ Perguntas } & \multicolumn{2}{|c|}{ Sempre } & \multicolumn{2}{|c|}{ Frequentemente } & \multicolumn{2}{|c|}{ Algumas vezes } & \multicolumn{2}{|c|}{ Raramente } & \multicolumn{2}{|c|}{ Nunca } & \multicolumn{2}{|c|}{ Total } \\
\hline & & $\%$ & $\mathrm{~N}$ & $\%$ & $\mathrm{~N}$ & $\%$ & $\mathrm{~N}$ & $\%$ & $\mathrm{~N}$ & $\%$ & $\mathrm{~N}$ & $\%$ & $\mathrm{~N}$ \\
\hline 1 & $\begin{array}{l}\text { Você demonstra abertamente a sua } \\
\text { orientação sexual no ambiente } \\
\text { acadêmico? }\end{array}$ & $36,70 \%$ & 44 & $19,2 \%$ & 23 & $14,2 \%$ & 17 & $19,2 \%$ & 23 & $10,8 \%$ & 13 & $100 \%$ & 120 \\
\hline 2 & $\begin{array}{c}\text { Você, em algum momento, já se } \\
\text { sentiu excluído(a)/rejeitado(a) dentro } \\
\text { do Centro Universitário por causa da } \\
\text { sua orientação sexual? }\end{array}$ & 0 & 0 & $1,7 \%$ & 2 & $14,2 \%$ & 17 & $11,7 \%$ & 14 & $72,5 \%$ & 87 & $100 \%$ & 120 \\
\hline 3 & $\begin{array}{l}\text { Dentro do Centro Universidade você } \\
\text { já sofreu/sofre } \\
\text { discriminação/preconceito por causa } \\
\text { da sua orientação sexual? }\end{array}$ & 0 & 0 & $0,8 \%$ & 1 & $4,2 \%$ & 5 & $8,3 \%$ & 10 & $86,7 \%$ & 104 & $100 \%$ & 120 \\
\hline 4 & $\begin{array}{l}\text { Você, em algum momento da vida, } \\
\text { sofreu/sofre } \\
\text { discriminação/preconceito por causa } \\
\text { da sua orientação sexual? }\end{array}$ & 0 & 0 & $16,7 \%$ & 20 & $17,5 \%$ & 21 & $4,2 \%$ & 5 & $61,70 \%$ & 74 & $100 \%$ & 120 \\
\hline 5 & $\begin{array}{c}\text { Você se sente/sentiu constrangido/a } \\
\text { ou inseguro(a)/constrangido(a) no } \\
\text { ambiente acadêmico por causa da } \\
\text { sua orientação sexual? }\end{array}$ & $2,50 \%$ & 3 & $4,2 \%$ & 5 & $13,3 \%$ & 16 & $10 \%$ & 12 & $70 \%$ & 84 & $100 \%$ & 120 \\
\hline 6 & $\begin{array}{l}\text { Você pensa, já pensou em desistir } \\
\text { do curso por algum conflito interno } \\
\text { ou externo relacionado à sua } \\
\text { orientação sexual? (Ex: expulso (a) } \\
\text { de casa; vítima de preconceito; } \\
\text { adquiriu depressão; etc.) }\end{array}$ & $3,30 \%$ & 3 & $4,2 \%$ & 5 & $5,8 \%$ & 7 & $5,8 \%$ & 7 & $80,80 \%$ & 97 & $100 \%$ & 120 \\
\hline
\end{tabular}

Legenda: \%: porcentagem e N: número.

Fonte: Capucce VS, et al., 2021. 


\section{DISCUSSÃO}

A partir dos dados obtidos nota-se que a prevalência de mulheres na presente Instituição de ensino superior é de 64,2\%, demonstrando um número superior a presença feminina nas Instituições Federais de Ensino Superior com uma porcentagem de 54,6\% (BRASIL, 2019). Com base no mesmo autor, ao comparar a média de idade entre os estudos, verifica semelhança, visto que, em 2018 a faixa etária média era de 24 anos e o levantamento de dados demonstrou uma idade média de 20 anos.

Foi observado que $84,2 \%$ dos entrevistados não trabalham, $42,5 \%$ dispõem de uma renda mensal igual ou superior a 5 salários mínimos e a maioria dos pais possuem curso superior e pós-graduação e $53,7 \%$ estudaram em escola privada. Tais dados convergem para o discutido pelo Conselho Federal de Medicina, uma vez que, a maioria dos recém-formados, médicos, brasileiros, estudaram em escolas privadas, moram com os pais que possuem ensino superior e um terço vem de famílias com renda mensal entre três a dez salários mínimos (SCHEFFER M, 2018).

Ao analisar esses dados, comparando com os estudantes de enfermagem, indica que $97,6 \%$ não possuem vínculo empregatício, $88,4 \%$ dependem dos pais para sustento mensal e possuem uma renda mensal média entre 5 a 10 salários mínimos (GARCIA AKA, et al., 2016), visualizando um cenário distinto ao que ocorre nos cursos com aulas no período noturno, em que se sobressai chefes de famílias, com média de idade de 25 anos, sugerindo a entrada mais tardia no ensino superior e mais dificuldade na permanência (FREITAS AASM, 2005). Ao passo que se analisa a permanência na instituição que é resultado da interação de fatores pessoais, familiares, sociais, econômicos e institucionais (COSTA SL e DIAS SMB, 2015).

A estabilidade financeira apresentada pela maior parte dos entrevistados corrobora para adaptação acadêmica, permanência no curso e satisfação com a escolha do curso (AMBIEL RAM e BARROS RO, 2018). Diante disso, foi possível inferir que $59,2 \%$ não necessitam de receber nenhuma bolsa para contribuir com a permanência na instituição e 48,8\% considera regular o favorecimento da permanência na graduação.

Com base nisso, destaca-se a necessidade de um olhar mais abrangente sobre os possíveis motivos que levou ao número expressivo que considera a regular a permanência da graduação. Avaliando a orientação sexual dos entrevistados, $23,3 \%$ se declararam homossexual e $20,8 \%$ bissexual. O que permite inferir que de acordo com (FERREIRA CC, 2015) que uma considerável fração dos ambientes educacionais ainda não estão preparados para lidar com os distintos modos e expressões que a sexualidade pode assumir.

Quando há um grupo vulnerável em um ambiente há maior propensão para subordinação e sentimento de inferioridade, este fato transforma esses indivíduos em passíveis de sofrer exclusão, maus tratos, aumento do estigma e discriminação (LIMA TNB, et al., 2019).

Questionando se já presenciaram ou souberam de algum episódio de discriminação, 40,5\% de gênero no âmbito da vida universitária, o que nos aponta que este tipo de violência é recorrente para os indivíduos entrevistados e de forma similar podemos compreender que tais violências compreendem, além de homofobia, uma sistemática ruptura com os direitos fundamentais dos seres humanos. E mais, tais elementos serem presentes na vida de acadêmicos - sua maioria de classe média alta - nos diz que a homofobia perpassa formações e classes econômicas enquanto categoria excludente e violenta.

Essa realidade, quando observada do ponto de vista da formação acadêmica dos futuros médicos e enfermeiros, nota-se fragilidade do ensino, visto que, é necessário a educação de gênero e sexualidade para atender aos pacientes ao longo da vida laboral (MIRANDA TS, et al., 2020). Assim, essa população acadêmica se não conseguem respeitar a diversidade dentro do seu nicho, questiona-se a aplicação desse respeito após formados.

Desse modo, a implementação de discussões acerca da orientação sexual e identidade de gênero possui como estratégia importante a inclusão da temática como conteúdo da grade curricular dos profissionais de saúde, como forma de naturalizar as manifestações as diversas manifestações de sexualidade promovendo atendimento pautado na equidade, integralidade e universalidade (MIRANDA TS, et al., 2020). No entanto, para Lima TNB (2019), os serviços de saúde fundados nesse princípio não podem cogitar a orientação sexual e identidade de gênero como atributos identitários ou marcadores sociais únicos, mas sim articulados com outros fatores. 
Vale ainda elencar que a partir da análise dos dados é notório uma prevalência de discentes que se declaram heterossexuais, $55,8 \%$, enquanto homossexuais e bissexuais são, respectivamente, $23,3 \%$ e $20,8 \%$. Nesse contexto é cabível inferir algumas outras informações para uma reflexão acerca do exposto, em que embora a maior parte sejam de heterossexuais, $40 \%$ admitem já ter presenciado ou saber de episódios de discriminação/preconceito contra pessoas LGBT no ambiente universitário, o que expõe uma questão alarmante, que embora o grupo que sofre preconceito seja a minoria representada na pesquisa, há um reconhecimento coletivo de preconceito ocorrido. Diante disso, caso houvesse um equilíbrio entre os gêneros dos entrevistados esse dado poderia ser ainda maior.

Os nossos resultados evidenciam que $36,7 \%$ dos entrevistados demonstra abertamente a sua orientação sexual no ambiente acadêmico, a grande maioria afirma que nunca se sentiu excluído ou rejeitado, $72,5 \%$. Contudo, tendo em vista que a predominância é heterossexual tal resultado responde a um padrão esperado, partido da heteronormatividade enquanto balizador das experiências sociais e sexuais da sociedade brasileira (LIMA CLS e FERNANDES ER, 2019).

O que vale destacar é a percepção dos entrevistados que pontuaram já terem se sentido, ou sentir-se constrangido ou inseguro no ambiente acadêmico por causa da sua orientação sexual, $20 \%$ variando entre frequentemente e as vezes, reforçando nossa análise de que mesmo em ambientes de classes sociais privilegiadas (considerando a distribuição e desigualdade econômica no Brasil) e de formação superior (Medicina/Enfermagem) há espaço para discursos excludentes pautados no gênero, nossos dados corroboram com o trabalho de Pereira GR e Bahia AGMF (2011) que afirma ser o ambiente educacional o terceiro lugar onde há maior incidência de preconceito.

De acordo com algumas revisões de literatura no contexto da graduação, envolvendo estudos brasileiros e internacionais, que apontam percentuais entre 15 a 29\% de discentes universitários apresentando algum tipo de transtorno psiquiátrico durante sua vida acadêmica (CAVESTRO JM e ROCHA FL, 2006; CERCHIARI EAN, et al., 2005; FONSECA AA, et al., 2008). Atrelado a isso, a questão de gênero ainda pode ser mais uma variável pertinente para contribuir para exacerbar ainda mais esses transtornos, como ansiedade, depressão. Sendo a sexualidade importante razão de nossa existência e parte de nossa identidade social integrativa e negativa, cabe a construção de um espaço saudável de sociabilização das formas de ser-viver, especialmente na academia superior.

A partir do resultado obtido $13,3 \%$ dos participantes afirmaram em uma frequência variável entre sempre e algumas vezes, já terem pensado em desistir do curso por algum conflito interno ou externo relacionado à sua orientação sexual, em que alguns desses conflitos se enquadram a questão psicológica. Este valor é altíssimo quando consideramos a necessidade iminente do Brasil de formação de médicos e melhoria do acesso à saúde com esta profissão e dos demais agentes de saúde - sendo a violência de gênero um fenômeno que vai de encontro à democracia no ambiente da formação acadêmica a mesma vai de encontro com a democratização do acesso à saúde.

Baseado no supracitado e a partir dos resultados, o grupo iniciou um programa de extensão que realizarse-á por meio de roda de conversa virtual, via GoogleMeet, onde irá ocorrer o debate sobre as vivencias LGBT+ na faculdade, a fim de estimular e fortalecer o debate do tema no meio acadêmico.

\section{CONCLUSÃO}

Neste trabalho, foram abordados os desafios que o aluno LGBT+ enfrenta no ambiente acadêmico para permanecer no Ensino Superior. Desse modo, discorremos desde fatores socioeconômicos, até questões relacionadas à manifestação de sua sexualidade e inerentes à sua natureza, para isso, a pesquisa utiliza do recurso quantitativo como meio teórico-metodológico para obter suas conclusões. Em consonância, esta pesquisa constitui-se como um meio de documentar de que forma a fuga à heteronormatividade influencia negativamente no cotidiano de alunos LGBT+, realidade, por muitas vezes, invisibilizada. Não somente isso, a análise contribui também para fomentar a discussão acerca da temática nos ambientes científico e acadêmico, com o intuito de diminuir sua incidência e promover maior igualdade à comunidade LGBT+, em um futuro próximo. 


\section{REFERÊNCIAS}

1. AMBIEL RAM, BARROS LO. Relações entre evasão, satisfação com escolha profissional, renda e adaptação de universitários. Revista Psicologia: Teoria e Prática, 2018; 20(2): 254-257.

2. BRASIL. V Pesquisa Nacional de Perfil Socioeconômico e Cultural dos Graduandos das IFES. 2018. Disponível em: Andifes.org.br/wp-content/uploads/2019/05/V-Pesquisa-do-Perfil-Socioeconômico-dos-Estudantes-de-Graduaçãodas-Universidades-Federais-1.pdf. Acesso em: 17 out. 2018.

3. CALOU ALF. Vidas indestrutíveis: micropolíticas da pobreza na vida homossexual. Fractal: Revista de Psicologia, 2019; 31 (especial): 36-243.

4. CARRARA S, VIANNA ARB. "Tá lá o corpo estendido no chão...": a Violência Letal contra Travestis no Município do Rio de Janeiro. Physis: Rev. Saúde Coletiva, 2006; 16(2): 233-249.

5. CAVESTRO JM, ROCHA FL. Prevalência de depressão entre estudantes universitários. Journal of Brazilian Psiquiatry, 2006; 55(4): 264-267.

6. CARVALHO KG, et al. Comportamento suicida em minorias sexuais: prevalência e fatores associados. Revista Eletrônica Acervo Saúde, [S.L.], v. 11, n. 14, p. 1, 13 ago. 2019. Revista Eletronica Acervo Saude. http://dx.doi.org/10.25248/reas.e867.2019.

7. CERCHIARI EAN, et al. Utilização do serviço de saúde mental em uma universidade pública. Psicologia Ciência e Profissão, 2005; 25(2): 252-265.

8. CORTES HM, et al. Vivências de mulheres transgêneras de um município do recôncavo da Bahia. Revista Eletrônica Acervo Enfermagem, [S.L.], v. 1, p. 1, 23 out. 2019. Revista Eletronica Acervo Saude. http://dx.doi.org/10.25248/reaenf.e1871.2019.

9. COSTA SL, DIAS SMB. A permanência no ensino superior e as estratégias institucionais de enfrentamento da evasão1. Jornal de Políticas Educacionais, 2015; 9(17): 51-60.

10. FERREIRA CC, FERREIRA SPA. Vivências Escolares de Jovens Homossexuais Afeminados: Estratégias de Resistência e Permanência. Revista Tópicos Educacionais, 2015; 21(2): 103-138.

11. FONSECA AA, et al. Representações sociais da depressão em jovens universitários com e sem sintomas para desenvolver a depressão. Psicologia: Reflexão e Crítica, 2008; 21(3): 492-498.

12. FREITAS AASM. Acesso à Universidade: os alunos do ensino superior privado. Estudos em Avaliação Educacional, 2005; 16(31): 153-168

13. GARCIA AKA, et al. Perfil de estudantes ingressantes de um curso de enfermagem do Sul do Brasil: caracterização dos hábitos de leitura e estudo. Semina: Ciências Biológicas e da Saúde, 2016; 37(2): 47-55.

14. GOMES TMC, et al. Conhecimento dos estudantes de enfermagem do centro universitário Estácio de Sergipe sobre a população LGBTQIAP+. Revista Eletrônica Acervo Saúde, [S.L.], v. 13, n. 2, p. 1, 25 fev. 2021. Revista Eletronica Acervo Saude. http://dx.doi.org/10.25248/reas.e6406.2021.

15. LACERDA M, et al. Um Estudo sobre as Formas de Preconceito contra Homossexuais na Perspectiva das Representações Sociais. Psicologia: Reflexão e Crítica, 2002; 15(1): 165-178.

16. LIMA CLS, FERNANDES ER. "Existe índio gay?": a colonização das sexualidades indígenas no Brasil. Anuário Antropológico, 2019; 44(2): 379-382.

17. LIMA TNB, de et al. Atenção à Saúde da População LGBT numa capital nordestina. Revista Eletrônica Acervo Saúde, [F.L.], v. , n. 34, p. 1-12, out. 2019.

18. MIRANDA TS, et al. Disparidades em saúde da população LGBTQIA+: a atuação médica frente a este cenário. Revista Eletrônica Acervo Científico, [S.L.], v. 13, p. 1, 8 out. 2020. Revista Eletronica Acervo Saude. http://dx.doi.org/10.25248/reac.e4872.2020.

19. PEREIRA GR, BAHIA AGMF. Direito fundamental à educação, diversidade e homofobia na escola: desafios à construção de um ambiente de aprendizado livre, plural e democrático. Educar em Revista, 2011; 39: 51-71.

20. QUIJANO A. Colonialidade do poder, Eurocentrismo e América Latina. In: LANDER E. A colonialidade do saber: eurocentrismo e ciências sociais. Perspectivas latino-americanas. 1aㅡ edição. Buenos Aires: Consejo Latinoamericano de Ciencias Sociales, 2005; p. 117-142.

21. ROMERO MAE, JIMÉNEZ JRR. Estudiantes LGBT+ y profesores universitarios. Prácticas de inclusión y exclusión en la educación superior. Voces y Silencios. Revista Latinoamericana de Educación, 2020; 11(2): 7-29.

22. SANTOS LES, et al. Access to the Unified Health System in the perspective of male homosexuals. Revista Brasileira de Enfermagem, 2020; 73(2): 1-8.

23. SCHEFFER M, et al. Demografia Médica no Brasil 2018. Conselho Federal de Medicina, 2018; 1(4): 286.

24. VALENZUELA-VALENZUELA AV, CARTES-VELÁSQUEZ R. Ausencia de perspectiva de género en la educación médica. Implicaciones en pacientes mujeres y LGBT+, estudiantes y professores, 2019; 33(1): 59-67.

25. VIEIRA JUNIOR JI, ALMEIDA JP. Vivência LGBT Na UFERSA. TCC (Graduação em Ciência e Tecnologia) Universidade Federal Rural do Semiárido, Mossoró, 2019; 24 p.

26. VIEIRA M. "Quero poder existir": contornos da violência simbólica contra orientações sexuais não binárias entre universitários LGBT da universidade federal de Santa Catarina. 2015. Dissertação (Mestrado em Saúde Coletiva) Centro de Ciências da Saúde. Universidade Federal de Santa Catarina, Florianópolis, 2015; 106 p.

27. WALSH C. Interculturalidade crítica e pedagogia decolonial: in-surgir, re-existir e re-viver. In: CANDAU VM. Educação intercultural na América Latina: entre concepções, tensões e propostas. $2^{\underline{a}}$ edição. Rio de Janeiro: 7letras; 2009 ; $p 12-$ 43. 